\title{
Inhibition by Egb761 of the effect of cellphone radiation on the male reproductive system
}

\author{
Gevrek $\mathrm{F}^{1}$, Aydin $\mathrm{D}^{2}$, Ozsoy $\mathrm{S}^{3}$, Aygun $\mathrm{H}^{3}$, Bicer $\mathrm{C}^{1}$ \\ Department of Histology and Embryology, Faculty of Medicine, Gaziosmanpasa University, Tokat, Turkey. \\ seyma.ozsoy@hotmail.com
}

\begin{abstract}
OBJECTIVES: To determine the effects of Egb761 on testicular tissues and semen parameters in rats exposed to cellphone waves.

BACKGROUND: EGb761 has antioxidant properties as a free-radical scavenger. Cellphone electromagnetic radiation (EMR) induces oxidative stress in cells.

METHODS: Twenty-one Wistar albino male adult rats were divided into three groups (control, experimental, treatment), including seven rats in each. The experimental and treatment groups were exposed to cellphone EMR $(0.96 \mathrm{~W} / \mathrm{kg})$ for six weeks (4 hrs/day). Egb761 (100 mg/kg/day) was also added to the treatment. Testes, epididymal semen and blood plasma were used for analysis.

RESULTS: Exposure to cellular phone radiation resulted in a significant impairment in testicular morphometry and histological structure, reduction of total and motile sperm numbers and plasma testosterone level. Egb761 administration improved testicular damage and led to a marked increase in plasma testosterone levels and total and motile sperm numbers.

CONCLUSION: Male reproductive system is susceptible to cellphone radiation. Cellphone waves induce toxic effects in testicular tissues, impair spermatogenesis and cause an imbalance in testosterone hormone levels. Egb761 ameliorated these toxic effects by reversing testicular tissue damage, restoring normal spermatogenesis and hormone levels. This suggests that Egb761 is a potential therapeutic agent against EMR-induced male reproductive toxicity (Tab. 3, Fig. 6, Ref. 45). Text in PDF www.elis.sk. KEY WORDS: electromagnetic radiation, ginkgo biloba extract, sperm, testis, testosterone.
\end{abstract}

\section{Introduction}

Cellular phones are one of the sources of electromagnetic radiation (EMR). The measure of interaction of EMR with living tissues is defined as specific absorption rate (SAR), which is the unit value of the absorbed power turned into heat in tissues, expressed as the absorbed energy per kilogram $(\mathrm{W} / \mathrm{kg})(1,2)$. The World Health Organization (WHO) suggests a maximum of 0.1 $\mathrm{W} / \mathrm{kg}$ SAR values of cellphones in use range between 0.1 and 1.11 $\mathrm{W} / \mathrm{kg}$, and the usage of these phones has been increasing gradually as well. Cellphones' EMR penetrates tissues and can be a reason for health problems $(1,3-5)$.

People carry their cellphones in their pockets or hands, locations which are generally close to their genitals. Therefore, cellphones could negatively affect their reproductive systems (6). In

${ }^{1}$ Department of Histology and Embryology, Faculty of Medicine, Gaziosmanpasa University, Tokat, Turkey, ${ }^{2}$ Ministry of Labor, Ankara, Turkey, and ${ }^{3}$ Department of Physiology, Faculty of Medicine, Gaziosmanpasa University, Tokat, Turkey

Address for correspondence: S. Ozsoy, Department of Physiology, Faculty of Medicine, Gaziosmanpasa University, Tokat, Turkey.

Phone: +905522076554

Acknowledgments: This research was approved and supported by The Scientific Research Fund of Gaziosmanpasa University (Grant No. 2013/61) Tokat, Turkey. We would like to thank for the funding. spermatogenesis process, Follicle Stimulating Hormone (FSH), Luteinizing Hormone (LH), and Testosterone (T) have very important roles (7). Abnormalities and malfunctions associated with these hormones manifest themselves by impairments in sperm characteristics. Many factors, such as testicular torsion, infections, cryptorchidism, gonadal dysgenesis, varicocele, medication, and EMR can unfavorably affect spermatogenesis and lead to infertility (8). Chronic exposure to radiofrequency electromagnetic radiation of cell phone leads to defective testicular function that is associated with increased oxidative stress (9) and decreased gonadotropic hormones (FSH, LH, T) profile (10).

These pathologies cause oxidative damage, along with an increase in reactive oxygen radicals (ROS) and a decrease in antioxidant capacity (11). ROS target all structures of the cell, and especially the lipid membranes (12). Spermatozoa consist of a high rate of polyunsaturated fatty acids, and therefore they are easily affected by these factors (13). It has recently been reported that antioxidant capacity diminished in human semen depending on exposure to cellphone radiation, and as a result, fertilization potential could be diminished or destroyed $(11,14,15)$. On the other hand, it is stated that the effect of antioxidant substances can improve sperm quality and increase fertility $(16,17)$.

It was postulated that natural antioxidant molecule therapy attenuates oxidative stress-induced cell damage (18-21). EGb761, a standardized extract of Ginkgo biloba leaves, has antioxidant 
properties as a free-radical scavenger (22). Numerous pharmacologically active constituents have been extracted from the leaves of Ginkgo, such as flavones, biflavones, organic acids, and flavonoid glycosides. It is the diterpene lactones; however, including ginkgolides A, B, C, J, M and the sesquiterpene, biloablide. The ginkgolides also show varying degrees of potency as specific antagonists of platelet activating factor (PAF). Of the five naturally occurring ginkgolides, $\mathrm{B}$ is considered the most active from the point of view of antagonizing PAF (23). Among various compounds, ginkgolic acid C $17: 1$ and ginkgolic acid C $15: 1$ are the most abundant ones extracted from Ginkgo biloba leaves (24), its antitumor effects through the modulation of several oncogenic targets including attenuation of pathways involved in lipogenesis (25), cell cycle arrest and decrease of the Bcl-2/Bax ratio (26). It was found for the first time that ginkgolic acid inhibits both constitutive and inducible STAT3 (oncogenic transcription factor) activation leading to the suppression of cell proliferation and down-regulation of various gene products that prevent apoptosis and promote inflammation and metastasis in tumor cells (27).

Numerous studies with EGb761 have demonstrated a positive effect in increasing vasodilation and peripheral blood-flow rate in the capillaries of patients suffering from a variety of circulatory dysfunctions and inflammations. Moreover it has beneficial effects in the treatment of neurological, cardiovascular, age-related and various diseases $(28,29)$. Thus, the aim of this study was to investigate the therapeutic effect of EGb761 on cellphone-EMRinduced testicular damage and impairment of sperm production in adult male rats.

\section{Materials and methods}

The experimental protocol was approved by the Animal Ethics Committee of Gaziosmanpasa University. Twenty-one adult male Wistar albino rats (350-400 g) were purchased from the Experimental Medicine Research Centre at Gaziosmanpasa University. The rats were divided into three groups (control, experimental/ test, treatment) of seven rats each. The center where the animals were housed was maintained at $22-24{ }^{\circ} \mathrm{C}$ with $50-65 \%$ relative humidity under a $12 \mathrm{~h}$ light/dark cycle. The animals were allowed free access to food and water. Rats in the control group were not

Tab. 1. Histological criteria for the modified Johnsen Scoring system.

\begin{tabular}{cl}
\hline Score & Histological criteria \\
\hline 1 & No cells within seminiferous tubules \\
\hline 2 & No germ cells, there are only Sertoli cells \\
\hline 3 & Only spermatogonia as germ cells \\
\hline 4 & No spermatozoa and spermatids, there are a few spermatocytes \\
\hline 5 & No spermatozoa and spermatids, there are many spermatocytes \\
\hline 6 & No spermatozoa, and there are a few (less than 10) spermatids \\
\hline 7 & $\begin{array}{l}\text { No spermatozoa, there are no late spermatids but many early } \\
\text { spermatids }\end{array}$ \\
\hline 8 & Late spermatids without any mature spermatozoa \\
\hline 9 & $\begin{array}{l}\text { Slightly impaired spermatogenesis, many late spermatids, disor- } \\
\text { ganized epithelium }\end{array}$ \\
\hline 10 & Full spermatogenesis \\
\hline
\end{tabular}

subject to cellphone radiation or any chemical substance application. Rats in the test and treatment groups, in polycarbonate cages, were kept between two cellphones (Nokia 3310, NHM-5NX) in talk mode with each other. Each phone, emitting EMR-RF in 0.96 $\mathrm{W} / \mathrm{kg}$ SAR value, was positioned $50 \mathrm{~cm}$ from the cages. These rats were exposed to cellphone EMR for six weeks ( 2 hrs a.m. + 2 hrs p.m./day). Egb761 (100 mg/kg/day, ip) (TriPharma Drug, Turkey) was also given to the treatment group during the experimental period. At the end of the study, the rats were killed and the testicles and the epididymis were harvested. The testes were placed in Bouin solution for immediate histological analyses. After transecting the proximal vas deferens, the sperm of each rat was allowed to passively flow into a Petri dish for evaluation of sperm number, motility, and morphology. For biochemical analyses, approximately $5 \mathrm{cc}$ blood was taken from the heart ventricle of the rats by an injector into biochemical tubes.

\section{Morphometric examination}

At the end of the study, after the separation of the testes, these were evaluated macroscopically and morphometrically. For this purpose, as soon as the testes were removed, their length and width were measured by a sensitive compass. Two separate measurements were made for each testis; the averages of these measurements were taken and recorded as a value belonging to each rat.

\section{Histological examination}

The testes were fixed in Bouin fixative. The tissues were subject to routine histological procedures and embedded in paraffin blocks. They were cut in $5 \mu \mathrm{m}$ thick slices by microtome (Leica RM 2135, Germany). Slices were stained with hematoxylin-eosin. The sections were analyzed for the general architecture, spermatogenesis, the basement membrane of seminiferous tubules, and the presence or absence of Leydig cell hyperplasia. Seven rats from each group and seven sections and a minimum of twenty seminiferous tubules in each testis were evaluated and the mean Johnsen score was calculated (30). Histological criteria for the modified Johnsen Scoring are described in Table 1.

\section{TUNEL assay}

We conducted a TdT-mediated deoxyuridine triphosphate nick end-labelling (TUNEL) staining to see how the apoptosis level in the testes would change with cellphone EMR. The TUNEL staining assay kit (In Situ Cell Death Detection Kit, AP; Roche) and all associated procedures were performed according to the manufacturer's instructions. Briefly, five- $\mu$ m-thick sections were deparaffinized, rehydrated and $750 \mathrm{~W}$ microwave irradiation was applied for $1 \mathrm{~min}$. Then, they were immersed for $30 \mathrm{~min}$ at room temperature in Tris-HCL, $0.1 \mathrm{M}, \mathrm{pH}$ 7.5. After being rinsed with PBS and having the excess fluid drained off, $50 \mu \mathrm{L}$ of the TUNEL reaction mixture (for the negative control $50 \mu \mathrm{L}$ Label solution) was added and slices were incubated for $60 \mathrm{~min}$ at $37{ }^{\circ} \mathrm{C}$ in a humidified atmosphere in the dark. After the samples were rinsed with PBS, Converter-AP was added to them. They were incubated in a humidified chamber for $30 \mathrm{~min}$ at $37^{\circ} \mathrm{C}$ and then rinsed with PBS; Substrate Fast Red solution was added, and the slices were incu- 
Tab. 2. Average group values of morphometric measurements of the testes ( \pm : SD, Statistically significant; * $\mathbf{p}<0.05$ ).

\begin{tabular}{lccc}
\hline & Length $(\mathrm{cm})$ & Width $(\mathrm{cm})$ & Length + Width $(\mathrm{cm})$ \\
\hline Control & $2.09 \pm .09$ & $1.29 \pm .09$ & $3.37 \pm .14$ \\
Treated & $1.87 \pm .08^{*}$ & $1.21 \pm .04$ & $3.09 \pm .07^{*}$ \\
Test & $1.84 \pm .08^{*}$ & $1.19 \pm .04^{*}$ & $3.03 \pm .11^{*}$ \\
\hline
\end{tabular}

bated for $10 \mathrm{~min}$ at $15-20{ }^{\circ} \mathrm{C}$ in the dark. After being rinsed with PBS, slides were counterstained with hematoxylin and mounted under a glass coverslip. The investigators, blinded to the animal grouping, analyzed slices under a light microscope. The apoptotic index was obtained by counting the TUNEL positive cells (redstained nuclei) compared to all the visible cells at a 40x objective.

\section{Sperm evaluation}

In order to observe the harmful effects of chronic exposure to cellphone EMR on sperm cells and the effects of Egb761, numerical and morphological analyses of the epididymal spermatozoa of rats were made.

For numerical analyses, a few drops of sperm suspension were dropped on a Thoma slide and observation was made at 400X us- ing a phase contrast microscope in five randomly selected counting fields. The spermatozoa were evaluated in terms of number and motion parameters immediately after isolation from the epididymis. Sperm parameters, such as numbers, motility, etc. were expressed separately, adapting the parameters to the $2010 \mathrm{WHO}$ decisions (31).

For sperm morphological analyses, epididymal semen content was spread on a clean and grease-free slide. Diff-Quick staining was made and the spermatozoa were evaluated in terms of the modified Kruger Strict criteria for issues such as head, neck, and tail abnormalities with a microscope at $40 \mathrm{X}$ objective (32). A minimum of 200 spermatozoa were counted for each animal by two different researchers.

\section{Biochemical examination}

While the rats were under deep anesthesia, blood samples of approximately $5 \mathrm{cc}$ were taken from the rats into biochemical tubes for hormonal analyses. After the blood coagulated, the samples were centrifuged at $4{ }^{\circ} \mathrm{C}$ and $1500 \mathrm{~g}$ for $15 \mathrm{~min}$. Serum was placed in Eppendorf tubes and kept at $-80^{\circ} \mathrm{C}$ until analysis. Serum LH and $\mathrm{T}$ hormone levels were measured in all groups according to
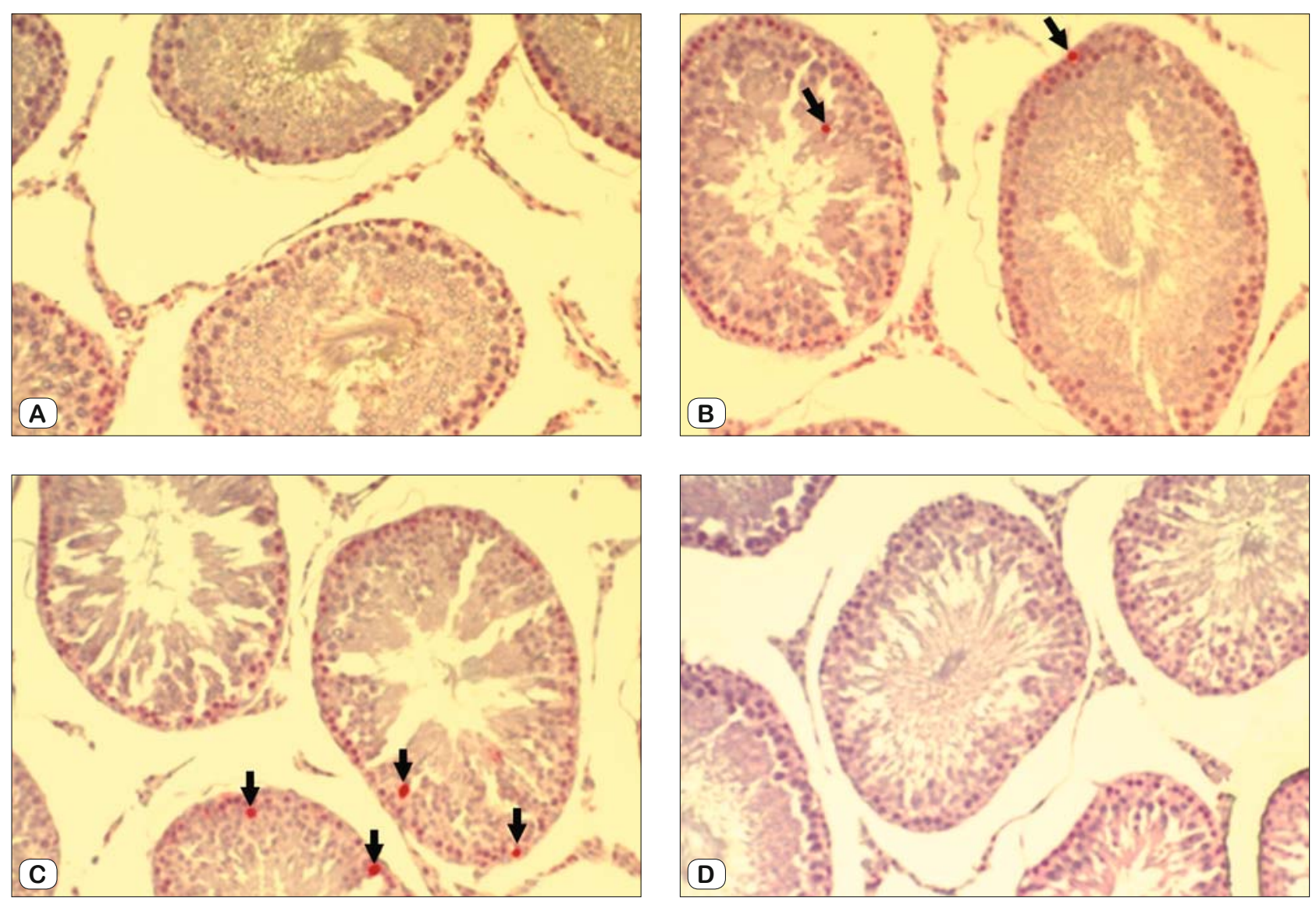

Fig. 1. View of seminiferous tubules and apoptotic cells with TUNEL staining of the testes

A) Control; normal seminiferous tubule and interstitial tissue are illustrated. B) Treatment group; it is observed that seminiferous tubule and interstitial tissues are affected and observation frequency of apoptotic cells increased in comparison to the control group, although only slightly. C) Experimental group; it is observed that damage in seminiferous tubules and interstitial tissues increased even more, and therefore observation frequencies of the apoptotic cells increased. D) Negative control (the arrows show apoptotic cells, Bar: $100 \mu \mathrm{m}$ ). 


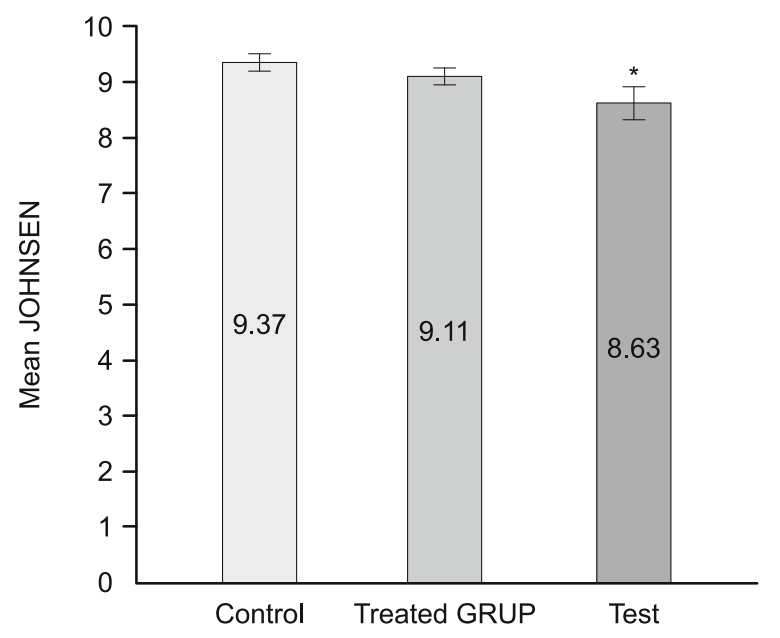

Fig. 2. Average testicular Johnsen scores of the groups (statistically significant; * $\mathbf{p}<0.05)$.

the manufacturer's information by LH (Elecsys LH kit; Roche Diagnostics), T (Elecsys Testosterone kit; Roche Diagnostics, Mannheim, Germany), ELISA kits, and the Cobas 6000 autoanalyzer (Cusabio Biotech, Wuhan, Hubei, China) equipment. LH was estimated in IU/L and T was estimated in $\mathrm{ng} / \mathrm{mL}$.

\section{Statistical analysis}

The statistical analyses were performed using the SPSS Statistics 20 package program (IBM Co., Somers, NY, USA) and the data were expressed as mean \pm standard deviation. Normal distributions of the data were analyzed by using a Kolmogorov-Smirnov test. Multiple comparisons between the groups were made after a one-way ANOVA by post hoc multiple comparison tests. In the comparison of biochemical data, one-way analysis of variance was used. A value of $\mathrm{p}<0.05$ indicated a significant difference.

\section{Results}

\section{Morphometric result}

Testes lengths were significantly decreased in the EMR and treatment groups $(p=0.001)$. Widths of the testes decreased only in the test group $(p=0.027)$. Although the treatment group measurement results decreased somewhat, they were statistically similar to the control $(p=0.096)$. When the length and width were evaluated together, there was a distinct decrease in the test and treatment groups $(\mathrm{p}=0.001)$. Although there was some level of decrease observed in the treatment group, it was not statistically significant (Tab. 2). An HSD test was used.

\section{Histopathological results}

The testes of the control group rats had a generally normal tissue appearance. In the test group, both germinal epithelial cell disarray and some basal membrane detachments were remarkable. Moreover, in those testes that were empty or with rare germinal cells, coagulative necrosis was observed. The integrity of

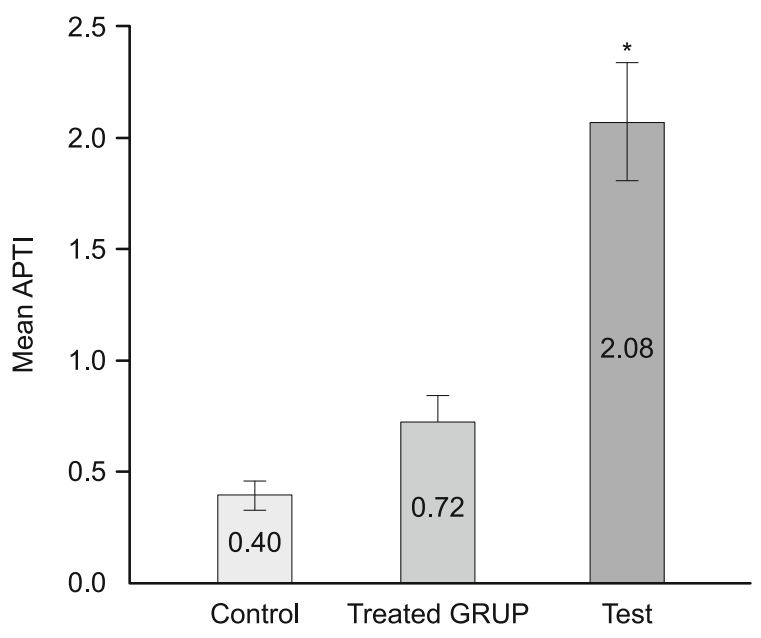

Fig. 3. Mean Seminiferous Tubule Apoptotic Index (API) of the groups (Statistically significant; * $\mathbf{p}<\mathbf{0 . 0 5}$ ).

interstitial tissue was destroyed and there was a slight edema, congestion, pale Leydig cells, and numerous blood cells in some areas. In the treatment group, although similar histopathological findings were observed in some areas, testis tissues were slightly restored and most of the tubules were intact and consisted in all spermatogenic series. Interstitial tissues were mostly of a normal histological pattern (Fig. 1).

In line with these histopathological results, Johnsen scores were lower in the experimental group than in the other groups, and this was statistically significant $(\mathrm{p}=0.004)$. Although the Johnsen score average of the treatment group (9.11) decreased in comparison to the control group (9.37) and the test group (8.63), it was not statistically significant $(\mathrm{p}=0.089, \mathrm{p}=0.055)$ by a Tamhane test (Fig. 2).

\section{Apoptotic index}

In the experimental group, seminiferous tubule API was observed to be statistically increased in comparison to the other groups $(p=0.001)$. In the treatment group there was some increase in comparison to the control in terms of seminiferous tubule apoptotic cell numbers; however, these two groups were not statistically different $(p=0.197)$. In the control group, the API was the lowest. It was estimated that the APIs of Egb761 and the control groups were statistically similar to each other by a Tukey HSD test (Figs 1-3).

\section{Sperm characteristics}

Stabile spermatozoa numbers were reduced in the test group and statistically different from the other groups $(p=0.011)$, but the treatment group was similar to the control $(\mathrm{p}=0.092)$. Motile spermatozoa numbers decreased significantly $(p=0.010)$ in the experimental group compared to the control. There was some increase in Egb761; however, it was not statistically different from the other groups $(p>0.05)$. Total spermatozoa counts of the Egb761 and control groups were statistically the same, and the 
Tab. 3. Average group values of spermiogram counting results ( \pm : SD, Statistically significant; * $\mathbf{p}<\mathbf{0 . 0 5})$.

\begin{tabular}{lcccc}
\hline & \multicolumn{4}{c}{ Sperm number $\times 10^{6} / \mathrm{ml}$} \\
\cline { 2 - 5 } & Motile & Non-motile & Total & $\%$ Motile \\
\hline Control & $54.86 \pm 9$ & $104.43 \pm 11$ & $159.29 \pm 19$ & $34.44 \pm 2$ \\
Treated & $46.57 \pm 8$ & $99.57 \pm 19$ & $146.14 \pm 25$ & $32.07 \pm 4$ \\
Test & $41.28 \pm 8^{*}$ & $81.57 \pm 9^{*}$ & $122.86 \pm 15^{*}$ & $33.46 \pm 4$ \\
\hline
\end{tabular}

test group values decreased sufficiently so as to be different than the other two groups $(p=0.034)$. Motile spermatozoa percentages were not significantly different $(p=0.448)$ between the groups (Tab. 3). LSD test was used.

In terms of sperm morphologic criteria results, the rate of normal spermatozoa decreased significantly in the experimental group compared to both the control and treatment groups $(p=0.001)$. The decrease in the treatment group was not significant when compared with the control group, and these two groups were not different from each other $(p=0.145)$. The rate of total abnormal spermatozoa increased significantly in the experimental group in comparison to the other groups $(p=0.001)$. The increase in the Egb761 group was not statistically different from the control $(p=0.150)$. The rate of the spermatozoa with tail anomaly increased significantly in the test group in comparison to the control $(p=0.007)$. There was an increase in treatment group; however, it was not statistically different from the other groups $(p>0.05)$. The spermatozoa with neck anomaly increased in the EMR group compared to the control $(p=0.001)$ and treatment $(p=0.013)$ groups. The other two groups were not statistically different from each other $(\mathrm{p}=$ $0.19)$. There was no significant difference among groups in terms of spermatozoa with head anomalies. The average of normal sperm percentage decreased in the experimental group compared to the other groups $(\mathrm{p}<0.05)$. A slight decrease was found in the Egb761 group, but it did not differ from the control $(\mathrm{p}=0.47)$. LSD and Tamhane tests were used (Figs 4 and 5).
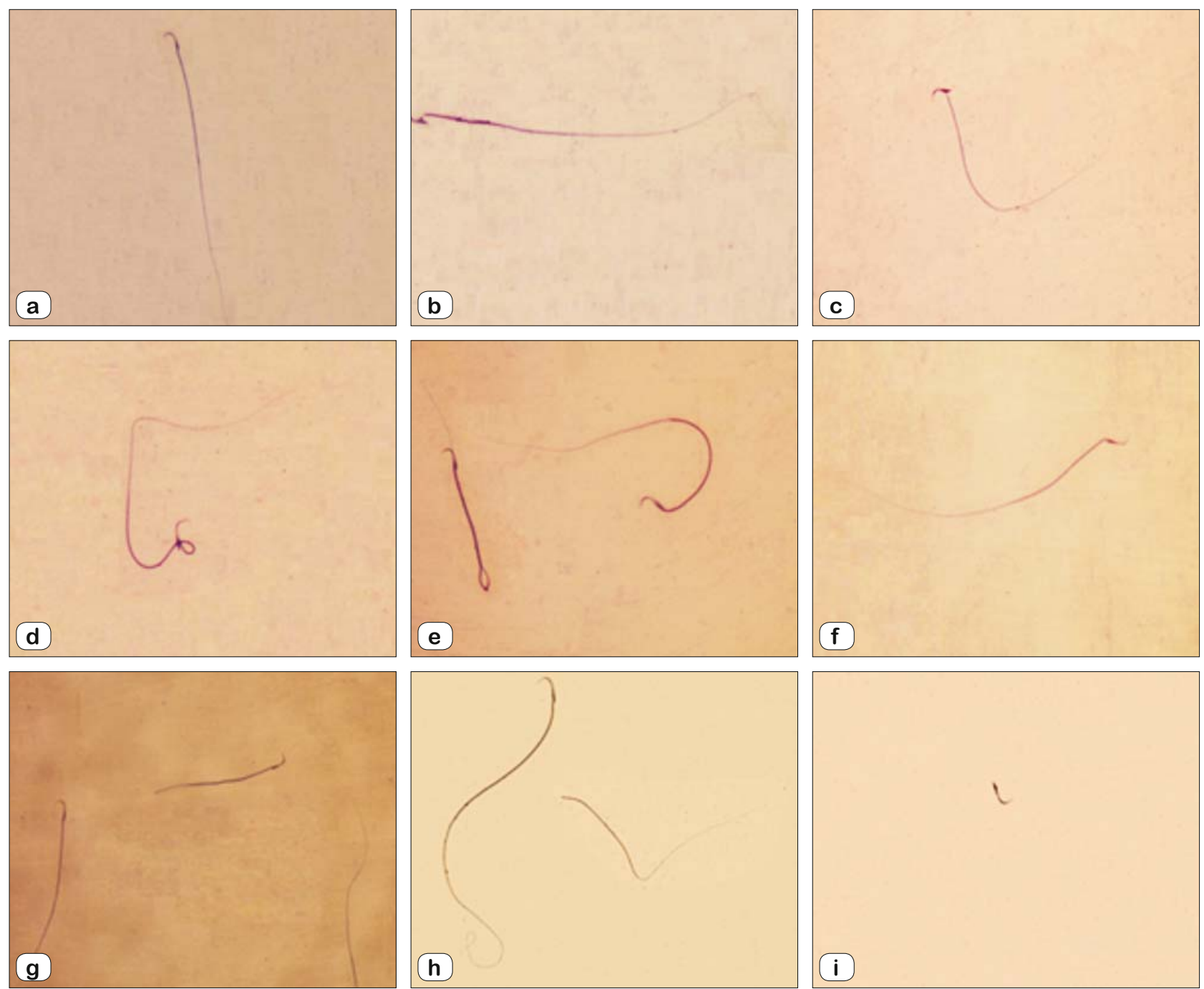

Fig. 4. Microscopic views of rat sperm morphologic disorders observed in all groups and especially frequently in the experimental group. a) Normal, b) Flattened heads and incorrect head-neck connection, c) Incorrect head-neck connection, d) Looping mid-piece, e) Folded principal piece and curved tail, f) Bent neck, g) Stubby tail, h) Coiled tail and headless, i: Tailless. (Bar $50 \mu \mathrm{m})$. 


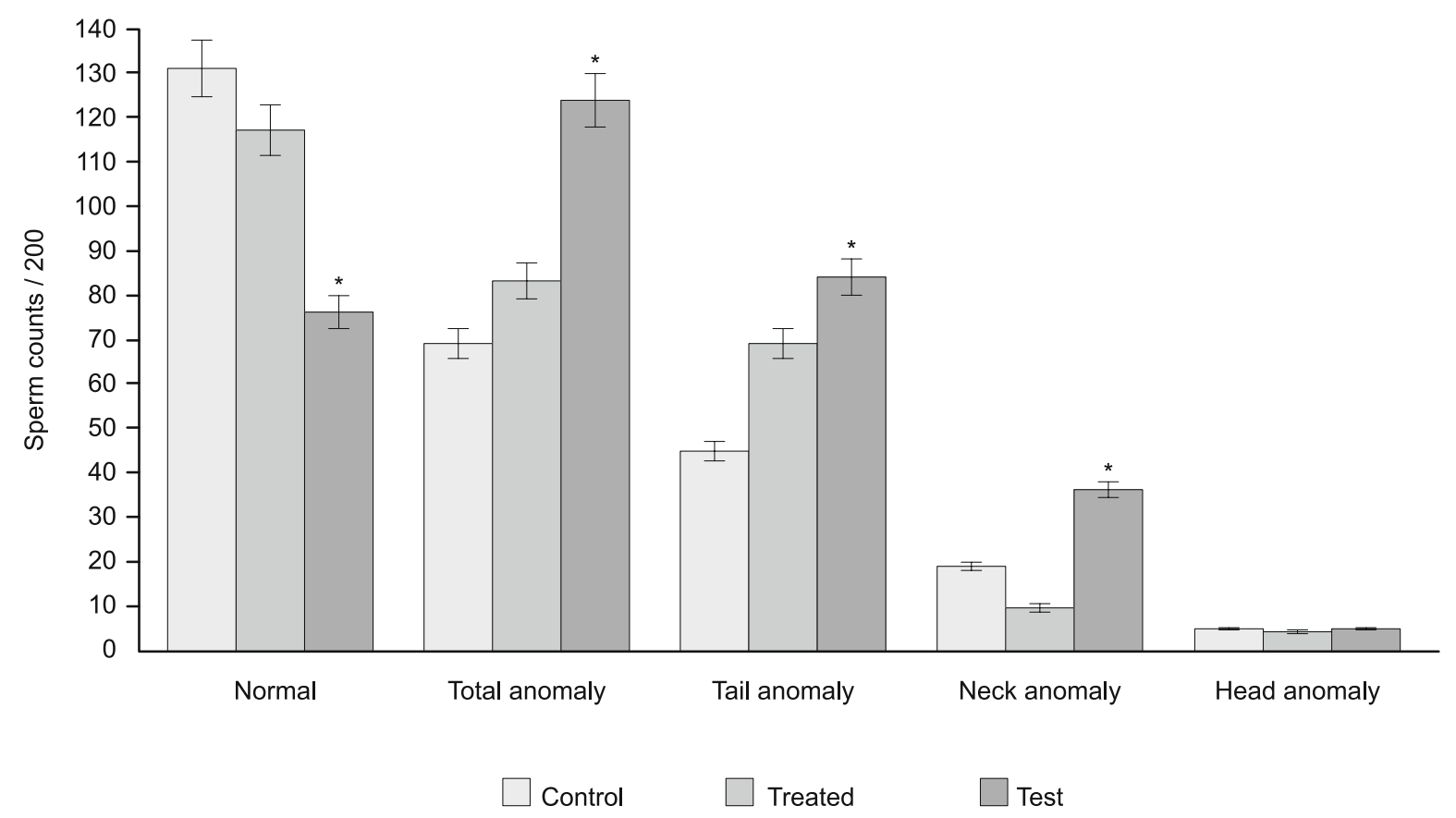

Fig. 5. Sperm morphology analysis results (Statistically significant; ${ }^{*} \mathbf{p}<0.05$ ).
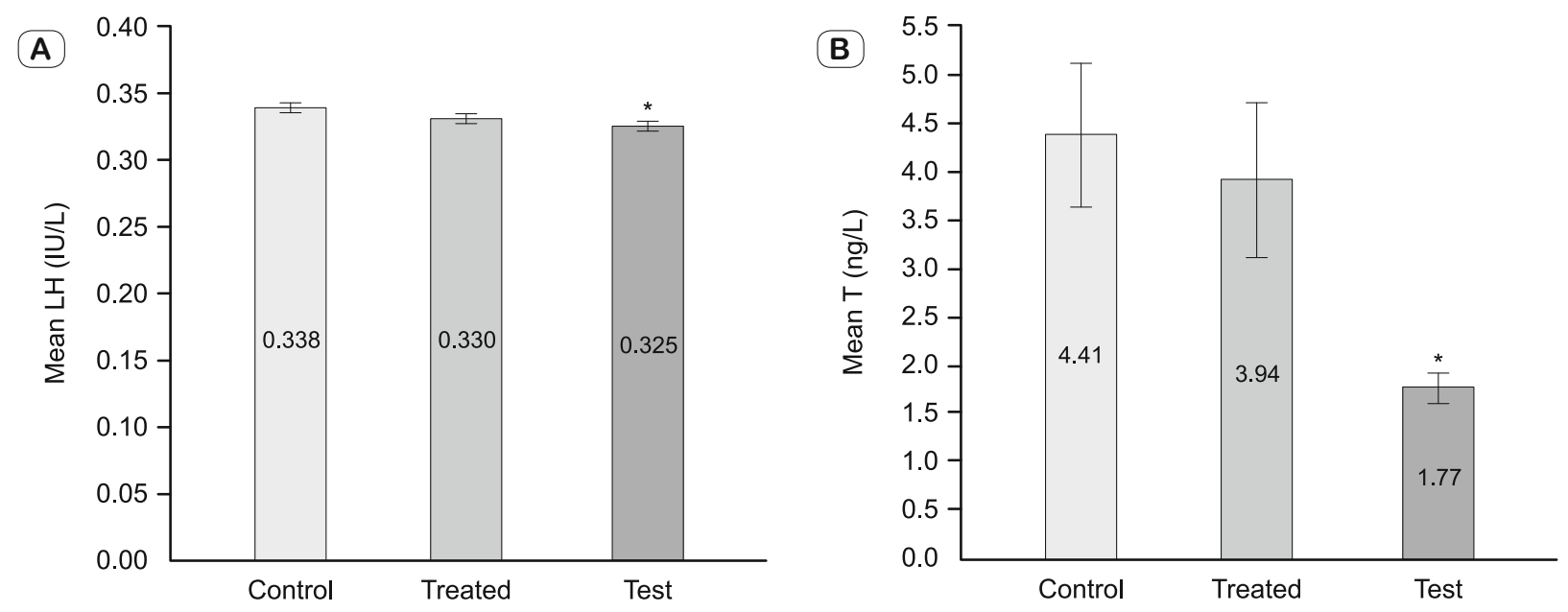

Fig. 6. Average values of serum LH (A) and T hormone (B) levels of the groups (statistically significant; * $p<0.05$ ).

\section{Biochemical results}

In the test group, when the average serum LH levels were compared with the control group, there was a significant decrease $(\mathrm{p}=$ $0.01)$. There was less of a decrease in treatment group in comparison to the control group in proportion to EMR; however, it was not statistically significant $(\mathrm{p}>0.05)$ (Fig. 6A). Mean serum T levels did statistically differ between the EMR and other groups. There was a statistically significant decrease in the experimental group when the control $(p=0.015)$ and treated groups $(p=0.040)$ were compared. There was some decrease in treated rats mean $T$ values, but this did not significantly differ from the control. Therefore, it was determined that this group was statistically the same $(p>0.05)$ as the control (Fig. 6B). Tukey HSD test was used.

\section{Discussion}

The etiology of the direct or indirect contribution of male factors in infertility is $50 \%$ and is solely responsible for $20-30 \%$ of human infertility (33). Problems related to sperm production can originate from many different factors such as hormonal, environmental, physical level within the testicle, causing problems with the seminiferous tubules. FSH, LH, and Thormones have a crucial role in spermatogenic processes; following stimulation with $\mathrm{LH}$, $\mathrm{T}$ is synthesized and used for spermatogenesis (7). If there are abnormalities of these hormones, spermatogenesis is disrupted (34). Many factors including obesity, temperature, environmental toxins, and technological devices, negatively affect spermatogenesis and 


\section{6-683}

could lead to male infertility $(5,35)$. It has been recently reported that cellphones could cause infertility as well $(36,37)$. Although the effects of cellphone EMR were investigated by many studies, some current results are controversial $(5,38)$.

Cellphone EMR waves induce oxidative stress and affect testicular structure and functions; (9) spermatogenesis is impacted $(11,39)$ and it may lead to future infertility. ROS formed as a result of oxidative stress in spermatozoa affect directly sperm motility and morphology as well (40-42). This may be the reason that the sperm parameters of rats exposed to cellphone radiation were negatively affected and histopathological damages in the testes increased. It was determined that Egb761 had a protective and therapeutic effect against many types of tissue damage and various diseases $(29,43,44)$. In this case, we also found that Egb761 alleviated the adverse effects of cellphones on testes and semen parameters. In the treatment group LH was increased, but not sufficiently. This may be due to the test period being of insufficient length. Significantly decreased LH in the EMR group suggested that cellphone radiation has a central effect on LH (hypothalamic or hypophyseal). Similar to the findings of Meo et al., we also observed a considerable decrease of T levels $(10,45)$, suggesting that cellphone waves had a negative effect on Leydig cells. That the treatment and control groups have close serum $\mathrm{T}$ levels also suggests that Egb761 protected Leydig cells from the cellphone EMR.

In sperm morphology evaluations, we observed a significant increase in the number of abnormal spermatozoa (except head abnormalities) in the experimental group. When the abnormalities were evaluated as a total, Egb761 had protective effect, but if they were analyzed separately, it did not have a statistically significant protective effect except against neck anomalies. The reason for this was that EMR's toxic degradation or elimination was delayed and the treatment was not fully effective. Many mechanisms might have played a role in this situation. If the treatments were applied for a longer period, a full recovery may have been observed.

As shown by the results of this study, exposure to cellphone EMR can have harmful effects on the testicular tissue, sperm production and activity, and T hormone production. Determination of the considerable reduction of total and motile sperm numbers of rats with cellphone exposure suggested that cellphone EMR waves could lead to infertility. However, an increase in sperm count and motility, T hormone level, mean Johnsen scores and decrease in mean testicular apoptotic index, abnormal forms of spermatozoa, testicular tissue damage were obtained with Egb761 application, which implies that it can be protective and therapeutic against the hazardous effects of mobile phone EMR.

In conclusion; in light of the biochemical, histological and hormonal findings, this study revealed that the male reproductive system is particularly susceptible to cellular phone EMR and it can be affected negatively as a result of prolonged exposure to cellular phone EMR. Cellular phone waves induce toxic effects on testicular tissues, impair spermatogenesis and cause an imbalance in gonadotropic hormones particularly T hormone levels. Egb761 ameliorated these toxic effects by reversing testicular tissue damage, restoring normal spermatogenesis and hormone levels. This suggests that Egb761 may be a potential protective and therapeutic agent against EMR-induced male reproductive toxicity. Nevertheless, further research is necessary on the elimination of EMR and the full mechanism of the process.

\section{References}

1. Hossain MI, Faruque MRI, Islam MT. Analysis on the effect of the distances and inclination angles between human head and mobile phone on SAR. Progr Biophys Mol Biol 2015; 119 (2): 103-110.

2. Ghanmi A, Varsier N, Hadjem A, Conil E, Picon O, Wiart J. Analysis of the influence of handset phone position on RF exposure of brain tissue. Bioelectromagnetics 2014; 35 (8): 568-579.

3. Motawi TK, Darwish HA, Moustafa YM, Labib MM. Biochemical modifications and neuronal damage in brain of young and adult rats after long-term exposure to mobile phone radiations. Cell Biochem Biophys 2014; 70 (2): 845-855.

4. Faruque MRI, Islam MT, Misran N. Analysis of electromagnetic absorption in mobile phones using metamaterials. Electromagnetics 2011; 31 (3): 215-232.

5. Zhang GW, Yan H, Chen Q et al. Effects of cell phone use on semen parameters: Results from the MARHCS cohort study in Chongqing, China. Environ Int 2016; 91: 116-121.

6. Mailankot M, Kunnath AP, Jayalekshmi H, Koduru B, Valsalan R. Radio frequency electromagnetic radiation (RF-EMR) from GSM (0.9/1.8 $\mathrm{GHz}$ ) mobile phones induces oxidative stress and reduces sperm motility in rats. Clinics 2009; 64 (6): 561-565.

7. Sofikitis N, Giotitsas N, Tsounapi P, Baltogiannis D, Giannakis D, Pardalidis N. Hormonal regulation of spermatogenesis and spermiogenesis. J Steroid Biochem Mol Biol 2008; 109 (3-5): 323-330.

8. Kaymak C, Kadioglu E, Coskun E, Basar H, Basar M. Determination of DNA damage after exposure to inhalation anesthetics in human peripheral lymphocytes and sperm cells in vitro by comet assay. Hum Exp Toxicol 2012; 31 (12): 1207-1213.

9. Kuzay D, Ozer C, Sirav B, Canseven AG, Seyhan N. Oxidative effects of extremely low frequency magnetic field and radio frequency radiation on testes tissues of diabetic and healthy rats. Bratisl Lek Listy 2017; 118 (5): 278-282.

10. Oyewopo AO, Olaniyi SK, Oyewopo CI, Jimoh AT. Radiofrequency electromagnetic radiation from cell phone causes defective testicular function in male Wistar rats. Andrologia 2017.

11. Liu Q, Si TL, Xu XY, Liang FQ, Wang LF, Pan SY. Electromagnetic radiation at $900 \mathrm{MHz}$ induces sperm apoptosis through bcl-2, bax and caspase-3 signaling pathways in rats. Reprod Health 2015; 12 (1): 65.

12. Desai NR, Kesari KK, Agarwal A. Pathophysiology of cell phone radiation: oxidative stress and carcinogenesis with focus on male reproductive system. Reprod Biol Endocrinol 2009; 7 (1): 114.

13. Sikka SC. Andrology lab corner: Role of oxidative stress and antioxidants in andrology and assisted reproductive technology. J Androl 2004; 25 (1): 5-18.

14. Kumar S, Nirala JP, Behari J, Paulraj R. Effect of electromagnetic irradiation produced by $3 \mathrm{G}$ mobile phone on male rat reproductive system in a simulated scenario. Indian J Exp Biol 2014; 52 (9): 890-897.

15. De Iuliis GN, Newey RJ, King BV, Aitken RJ. Mobile phone radiation induces reactive oxygen species production and DNA damage in human spermatozoa in vitro. PloS one 2009; 4 (7): e6446. 
16. Ibrahim SF, Osman K, Das S, Othman AM, Majid NA, Rahman MP. A study of the antioxidant effect of alpha lipoic acids on sperm quality. Clinics (Sao Paulo) 2008; 63 (4): 545-550.

17. Sheweita SA, Tilmisany AM, Al-Sawaf H. Mechanisms of male infertility: role of antioxidants. Curr Drug Metab 2005; 6 (5): 495-501.

18. Alpay M, Kismali G, Meral O, Sel T, Ozmerdivenli R, Pasin O. Antioxidant therapy impresses in oxidative stress-induced kidney cells. Bratisl Lek Listy 2017; 118 (2): 89-94.

19. Zakaria MMH, Hajipour B, Estakhri R, Saleh BM. Anti-oxidative effect of resveratrol on aluminum induced toxicity in rat cerebral tissue. Bratisl Lek Listy 2017; 118 (5): 269-272.

20. Nepali S, Ki HH, Lee JH, Lee HY, Kim DK, Lee YM. WheatgrassDerived Polysaccharide Has Antiinflammatory, Anti-Oxidative and AntiApoptotic Effects on LPS-Induced Hepatic Injury in Mice. Phytother Res 2017.

21. Soyaliç H, Gevrek F, Koç S, Avcu M, Metin M, Aladağ İ. Intraperitoneal curcumin and vitamin $\mathrm{E}$ combination for the treatment of cisplatin-induced ototoxicity in rats. Int J Pediatr Otorhinolaryngol 2016; 89: 173-178.

22. Mohamed NE-S, EI-Moneim AEA. Ginkgo biloba extract alleviates oxidative stress and some neurotransmitters changes induced by aluminum chloride in rats. Nutrition 2017; 35: 93-99.

23. Tredici PD. Ginkgos and people - a thousand years of interaction. Arnoldia (Boston) 1991; 51 (2): 2-15.

24. Li L, Yao QQ, Xu SY et al. Cyclosporin A affects the bioavailability of ginkgolic acids via inhibition of P-gp and BCRP. Eur J Pharm Biopharm 2014; 88 (3): 759-767.

25. Ma J, Duan W, Han S et al. Ginkgolic acid suppresses the development of pancreatic cancer by inhibiting pathways driving lipogenesis. Oncotarget 2015; 6 (25): 20993-21003.

26. Zhou C, Li X, Du W et al. Antitumor effects of ginkgolic acid in human cancer cell occur via cell cycle arrest and decrease the Bcl-2/Bax ratio to induce apoptosis. Chemotherapy 2010; 56 (5): 393-402.

27. Baek SH, Lee JH, Kim C et al. Ginkgolic Acid C 17: 1, Derived from Ginkgo biloba Leaves, Suppresses Constitutive and Inducible STAT3 Activation through Induction of PTEN and SHP-1 Tyrosine Phosphatase. Molecules 2017; 22 (2): 276

28. Chavez-Morales RM, Jaramillo-Juarez F, Rodriguez-Vazquez ML, Martinez-Saldana MC, Del Rio FAP, Garfias-Lopez JA. The Ginkgo biloba extract $(\mathrm{GbE})$ protects the kidney from damage produced by a single and low dose of carbon tetrachloride in adult male rats. Exp Toxicol Pathol 2017.

29. Zhang C, Wang DF, Zhang Z, Han D, Yang K. EGb 761 Protects Cardiac Microvascular Endothelial Cells against Hypoxia/Reoxygenation Injury and Exerts Inhibitory Effect on the ATM Pathway. J Microbiol Biotechnol 2017; 27 (3): 584-590.

30. Johnsen SG. Testicular biopsy score count - a method for registration of spermatogenesis in human testes: normal values and results in 335 hypogonadal males. Hormones 1970; 1 (1): 2-25.
31. WHO. WHO laboratory manual for the examination and processing of human semen. 5th ed Cambrige, UK: Cambridge University Press 2010.

32. Rezvanfar M, Sadrkhanlou R, Ahmadi A et al. Protection of cyclophosphamide-induced toxicity in reproductive tract histology, sperm characteristics, and DNA damage by an herbal source; evidence for role of free-radical toxic stress. Hum Exp Toxicol 2008; 27 (12): 901-910.

33. Agarwal A, Mulgund A, Hamada A, Chyatte MR. A unique view on male infertility around the globe. Reprod Biol Endocrinol 2015; 13 (1): 37.

34. Cai K, Hua G, Ahmad S et al. Action mechanism of inhibin alphasubunit on the development of Sertoli cells and first wave of spermatogenesis in mice. PloS one 2011; 6 (10): e25585.

35. Aktan G, Doğru-Abbasoğlu S, Küçükgergin C, Kadioğlu A, Özdemirler-Erata G, Koçak-Toker N. Mystery of idiopathic male infertility: is oxidative stress an actual risk? Fertil Steril 2013; 99 (5): 1211-1215.

36. Morielli T, O'Flaherty C. Oxidative stress impairs function and increases redox protein modifications in human spermatozoa. Reproduction 2015; 149 (1): 113-123.

37. Yan JG, Agresti M, Bruce T, Yan YH, Granlund A, Matloub HS. Effects of cellular phone emissions on sperm motility in rats. Fertil Steril 2007; 88 (4): 957-964.

38. Yildirim ME, Kaynar M, Badem H, Cavis M, Karatas OF, Cimentepe E. What is harmful for male fertility: cell phone or the wireless Internet? Kaohsiung Journal of Medical Sciences 2015; 31 (9): 480-484.

39. Agarwal A, Desai NR, Makker $K$ et al. Effects of radiofrequency electromagnetic waves (RF-EMW) from cellular phones on human ejaculated semen: an in vitro pilot study. Fertil Steril 2009; 92 (4): 1318-1325.

40. Guthrie HD, Welch GR, Long JA. Mitochondrial function and reactive oxygen species action in relation to boar motility. Theriogenology 2008; 70 (8): 1209-1215.

41. Sharma RK, Pasqualotto FF, Nelson DR, Thomas AJ, Agarwal A. Relationship between seminal white blood cell counts and oxidative stress in men treated at an infertility clinic. J Androl 2001; 22 (4): 575-583.

42. Salama N, Kishimoto T, Kanayama H. Effects of exposure to a mobile phone on testicular function and structure in adult rabbit (Retracted article. See vol. 35, pg. 629, 2012). Int J Androl 2010; 33 (1): 88-94.

43. Gu QH, Chen C, Zhang ZP et al. Ginkgo biloba extract promotes osteogenic differentiation of human bone marrow mesenchymal stem cells in a pathway involving Wnt/beta-catenin signaling. Pharmacol Res 2015; 97: 70-78.

44. Mesquita TR, de Jesus IC, dos Santos JF et al. Cardioprotective action of Ginkgo biloba extract against sustained $\beta$-adrenergic stimulation occurs via activation of M2/NO pathway. Front Pharmacol 2017; 8: 1-13.

45. Meo SA, Al-Drees AM, Husain S, Khan MM, Imran MB. Effects of mobile phone radiation on serum testosterone in Wistar albino rats. Saudi Med J 2010; 31 (8): 869-873.

Received June 5, 2017. Accepted July 4, 2017. 